Article

\title{
Experimental Study of the Viability of Low-Grade Biofuels in Small-Scale Appliances
}

\author{
Araceli Regueiro ${ }^{1, *}$ (D), Lucie Jezerská ${ }^{2} \mathbb{C}^{(\mathbb{D}}$, David Patiño $^{1}$, Raquel Pérez-Orozco ${ }^{1}$, Jan Nečas ${ }^{2}$ \\ and Martin Žídek ${ }^{2}$ \\ 1 Industrial Engineering School, University of Vigo, Campus Lagoas-Marcosende, s/n, 36310 Vigo, Spain; \\ patinho@uvigo.es (D.P.); rporozco@uvigo.es (R.P.-O.) \\ 2 VSB-TU Ostrava, Centre ENET, Bulk Solid Centre, 17. listopadu 15, 70833 Ostrava, Czech Republic; \\ lucie.jezerska@vsb.cz (L.J.); jan.necas@vsb.cz (J.N.); martin.zidek@vsb.cz (M.Ž.) \\ * Correspondence: aregueiro@uvigo.es; Tel.: +34-986-818-624
}

Received: 5 September 2017; Accepted: 6 October 2017; Published: 11 October 2017

\begin{abstract}
This experimental work aims to study the viability of making use of agricultural and forest residues as an alternative to produce biofuels for commercial devices. It focuses on the feasibility of three non-commercial biomass fuels in an underfed biomass pilot combustor with a power range of $7-12 \mathrm{~kW}_{\text {th }}\left(500-800 \mathrm{~kW} / \mathrm{m}^{2}\right)$. To carry out the investigation, the repeatability of the facility was studied using fuel with a high ash content. The relative deviations in the main parameters considered (combustion rate, gaseous emissions and particulate matter emissions) were below 10\%. A feasibility analysis was performed by comparing the result obtained with a barley and leaf pellet with that obtained with a commercial wood pellet as a reference. The parameters used in this study were the operational parameters of the plant as well as the particle concentration and distribution, fouling and slagging. Comparing the results of the different fuels, it was determined that $25 \%$ leaf $+75 \%$ wood pellet (lp25) could be used as a commercial pellet with the incorporation of an additive. However, the two other fuels presented undesirable behavior characterized by high particle concentrations and notable amounts of slag.
\end{abstract}

Keywords: biomass combustion; air-staging; slagging; fouling; biofuels

\section{Introduction}

In recent years, renewable energies have gained great importance. The growing increase in the price of fossil fuels and concern for the environment have powered the search for new energy resources [1]. New technologies and advances coming from research studies in the field of biomass have increased the use of pellets and briquettes in common applications of heat production in the domestic sector $[2,3]$. As a consequence of this growing use, the availability of biomass is decreasing. The majority of commercial pellets are made of wood, and it is useful to search for new raw materials for the production of pellets. Some studies have proven the validity of alternative sources with lower energy quality, including various agricultural residues such as apple pulp, red canary grass, waste pectin citrus peel, sunflower husk, wheat straw, bagasse, nutshell, hemp, salix, grass, tomatoes, chard and olive pits, among others [4-6]. Tests are normally conducted in small-scale commercial boilers $[7,8]$ but occasionally in pilot plants or experimental prototype burners [7-9].

The variables regularly taken into account to study the behavior of new resources are often based on the study of the chemical and mechanical/physical properties of the fuel [5]. The first examination includes a proximate and ultimate analysis of the fuel as well as an elemental analysis of the ashes. Some predictions into the behavior of the fuel are made based on these results [6,10]. If the fuels are tested in an actual combustor, pollutant emissions are recorded and verified to meet standards [4] for 
either gaseous or solid particle emissions. This last parameter becomes a key factor, and concentrations can reach up to $650 \mathrm{mg} / \mathrm{Nm}^{3}$ [4]. The mechanical/physical properties of raw input fuel materials are also important in the design of engineering constructions that are necessary for treatment and storage of the materials. For example, it is useful to know mechanical/physical parameters such as the particle-size distribution, flow properties, density and friction parameters for facile pelletization processes or briquetting.

Regarding the viability of different agricultural fuels, the study of slag is of great interest. Clinkering, or slag formation, is directly related to the fuel characteristics, especially the ash content. Therefore, fuels with high ash content will perform poorly at efficient combustion [5,6]. Verma et al. [4] carried out a slagging study in which the total amount of slag was related to the ash fuel content. Gilbe et al. [6] performed an analysis on collected slag samples using SEM, EDS and X-ray techniques to analyze the components mainly responsible for its production. Öhman et al. [10] determined that one of the main contributors to slag is the silicon ash content. Alkali silicates have a low melting point. Hence, because of the high temperatures reached in the combustion chamber, silicon based silicates will reach its melting point, causing notable slag formation. Therefore, numerous studies have performed XRF analysis of the ash composition. In this way, it is possible to establish a preliminary comparison of fuel suitability in relation to slag formation [8-11]. The presence of alkali metals, such as potassium, is also a prerequisite to begin the slag formation process [6,10,12]. Slag is accumulated in the bed after combustion and increases the cost of the energy produced due to unwanted or scheduled breaks for cleaning.

The main objective of this work is to determine if any of the non-commercial fuels analyzed (barley pellet, $100 \%$ leaf pellet or $25 \%$ leaf $+75 \%$ wood pellet) present promising behavior making them commercially viable, even if it were necessary to add small amounts of additives. To reach these conclusions, the obtained results were compared with the commercial wood pellet performance. To determine the viability, the following parameters were analyzed: burning rate and optimum air excess, gaseous emissions, concentration and distribution of emitted solid particles, and the quantity of slag and fouled matter accumulated in the bed and in the heat exchanger tube. A pilot combustor was used because it was considered more useful for a first approximation of the fuel viability. Numerous studies were previously conducted using the same experimental setup used in this research $[13,14]$. The facility is very versatile, as it allows the tuning of many parameters (primary air, secondary flow fuel, test time, and total amount of air) with good repeatability, therefore facilitating the determination of the optimal combustion parameters for each fuel.

\section{Methodology}

\subsection{Fuel}

\subsubsection{Chemical Characterization}

To carry out this study, four different fuels were used. As a reference, a commercial wood pellet $(w p)$ was utilized as the base case. The non-commercial pellets used were barley pellet (bp), $100 \%$ leaf pellet (lp100) and $25 \%$ leaf $+75 \%$ wood pellet (lp25). The barley pellet is made of grain crop residues. The leaf pellets were made up of leaves from urban areas (i.e., cities), as a seasonally available waste material. Leaves are a possible substitute or additive for wood. In Table 1, data related to the proximate analysis, ultimate analysis and ash composition are collected. According to the data, the fouling and slagging indices were obtained. 
Table 1. Proximate and elemental analysis, composition ash analysis, and fouling and slagging indices.

\begin{tabular}{|c|c|c|c|c|}
\hline \multicolumn{5}{|c|}{ Proximate Analysis ${ }^{1}$ (\%) } \\
\hline & wp & bp & $1 p 100$ & $1 p 25$ \\
\hline Moisture $^{2}$ & 7.33 & 6.92 & 7.74 & 9.79 \\
\hline Volatile & 68.02 & 63.06 & 56.58 & 59.54 \\
\hline Char & 24.10 & 21.62 & 22.71 & 23.42 \\
\hline Ash & 0.55 & 8.39 & 12.97 & 7.26 \\
\hline \multicolumn{5}{|c|}{ Elemental Analysis ${ }^{3}$ (\%) } \\
\hline $\mathrm{C}$ & 48.99 & 44.69 & 44.14 & 45.65 \\
\hline $\mathrm{H}$ & 6.45 & 6.03 & 5.55 & 6.35 \\
\hline $\mathrm{N}$ & 0.23 & 0.55 & 1.12 & 0.61 \\
\hline $\mathrm{O}^{4}$ & 43.73 & 39.72 & 35.14 & 39.35 \\
\hline$S^{5}$ & - & - & - & - \\
\hline \multicolumn{5}{|c|}{ Ash Analysis (wt \% of Dry Ash) } \\
\hline $\mathrm{Na}_{2} \mathrm{O}$ & 0.71 & 0.03 & 0.01 & 0.49 \\
\hline $\mathrm{MgO}$ & 9.45 & 1.62 & 0.60 & 3.80 \\
\hline $\mathrm{Al}_{2} \mathrm{O}_{3}$ & 12.23 & 0.46 & 0.70 & 8.56 \\
\hline $\mathrm{SiO}_{2}$ & 22.79 & 68.21 & 49.74 & 39.12 \\
\hline $\mathrm{P}_{2} \mathrm{O}_{5}$ & 3.05 & 1.24 & 0.53 & 2.74 \\
\hline $\mathrm{SO}_{3}$ & 6.68 & 2.78 & 0.69 & 2.42 \\
\hline $\mathrm{Cl}$ & 1.41 & 0.74 & 0.11 & 0.61 \\
\hline $\mathrm{K}_{2} \mathrm{O}$ & 16.63 & 13.98 & 1.43 & 8.95 \\
\hline $\mathrm{CaO}$ & 22.48 & 10.67 & 43.93 & 28.58 \\
\hline $\mathrm{TiO}_{2}$ & 0.58 & 0.02 & 0.19 & 0.42 \\
\hline $\mathrm{Cr}_{2} \mathrm{O}_{3}$ & - & - & - & 0.02 \\
\hline $\mathrm{MnO}$ & 1.38 & 0.04 & 0.55 & 0.41 \\
\hline $\mathrm{Fe}_{2} \mathrm{O}_{3}$ & 2.23 & 0.18 & 1.41 & 3.50 \\
\hline $\mathrm{NiO}$ & - & - & - & 0.01 \\
\hline $\mathrm{ZnO}$ & 0.26 & 0.01 & 0.08 & 0.11 \\
\hline $\mathrm{Rb}_{2} \mathrm{O}$ & - & - & - & 0.00 \\
\hline $\mathrm{SrO}$ & 0.13 & 0.03 & 0.05 & 0.07 \\
\hline $\mathrm{ZrO}_{2}$ & - & - & - & 0.01 \\
\hline $\mathrm{BaO}$ & - & - & - & 0.16 \\
\hline \multicolumn{5}{|c|}{ Fouling Index } \\
\hline Alkali index & 0.05 & 0.67 & 0.11 & 0.39 \\
\hline Base-acid ratio $\mathrm{B} / \mathrm{A}$ & 1.45 & 0.39 & 0.94 & 0.94 \\
\hline Slagging ratio $S_{R}$ & 40.02 & 84.54 & 51.99 & 52.15 \\
\hline Fouling ratio $\mathrm{F}_{\mathrm{U}}$ & 25.08 & 5.40 & 1.34 & 8.90 \\
\hline
\end{tabular}

${ }^{1}$ dry basis with ash; ${ }^{2}$ moisture is presented as received while the rest of the components are in dry basis; ${ }^{3}$ dry basis ash free; ${ }^{4}$ oxygen is calculated by the difference $\mathrm{O} \%=100-\mathrm{C} \%-\mathrm{H} \%-\mathrm{N} \%-A s h \% ;{ }^{5}$ sulfur is below that the equipment detection limit ( $\mathrm{DL}=30 \%$ ). The equipment detection limit for the rest of the elements is $10 \mathrm{ppm}$.

\subsubsection{Raw Input Materials}

Knowledge of the physical and flow properties of the raw input materials is essential for the design of reliable storage systems and equipment for handling these bulk solids. The basic characteristics were measured to predict the possibility of processing these alternative materials.

- Effective angle of internal friction, angle of wall friction, bulk density and flowability

The effective angles of internal friction, wall friction, bulk density and flowability were measured by a widely used device, a Ring Shear Tester (Schulze). The automatic computer-controlled RST-01 (Ring Shear Tester) instrument was designed by the German inventor Dr. Dietmar Schulz in agreement with established standards for the shear testing of bulk materials (according to ASTM-6773) [15]. The flowability was determined by the dimensionless flow index ffc. This dimensionless index is defined as the ratio between the consolidation stress $\left(\sigma_{1}\right)$ and the unconfined yield strength $\left(f_{c}\right.$ or 
$\sigma_{\mathrm{c}}$ ), and then, the material was classified according to the rules developed by Jenike in regards to the powder flowability group, as shown in Table 2 [15].

Table 2. Jenike classification of powder flowability by the flow index.

\begin{tabular}{lccccc}
\hline Flow Index & ffc $<\mathbf{1}$ & $\mathbf{1}<\mathrm{ffc}<\mathbf{2}$ & $\mathbf{2}<\mathrm{ffc}<\mathbf{4}$ & $\mathbf{4}<\mathrm{ffc}<\mathbf{1 0}$ & $\mathrm{ffc}>\mathbf{1 0}$ \\
\hline Flowability & Hardened (not flowing) & Very cohesive & Cohesive & Easy flowing & Free flowing \\
\hline
\end{tabular}

The measurement of the angle wall friction between a stainless-steel surface and the tested raw bulk materials was carried out using procedures similar to the measurement of the angle of internal friction. The bulk density was generated automatically by the Ring Shear Tester.

- Pelletization

The raw input materials were crushed by a hammer crusher (Green Energy 9FQ 50) to a suitable grain size. Then, a laboratory pellet press (KAHL 14-175) was used for pelletization. The pellet press has a flat die, and the diameter of the produced pellets was $6 \mathrm{~mm}$. A single die was used to maintain identical pelletizing conditions.

\subsection{Description of the Facility}

The general scheme and the different sections of the facility used to carry out this study are shown in Figure 1. The facility is an experimental biomass combustor with an under-feeding system and a staged air inlet. The combustor produces power within the range $7-12 \mathrm{~kW}\left(500-800 \mathrm{~kW} / \mathrm{m}^{2}\right)$. A more detailed description of the facility can be found in $[13,14,16]$.

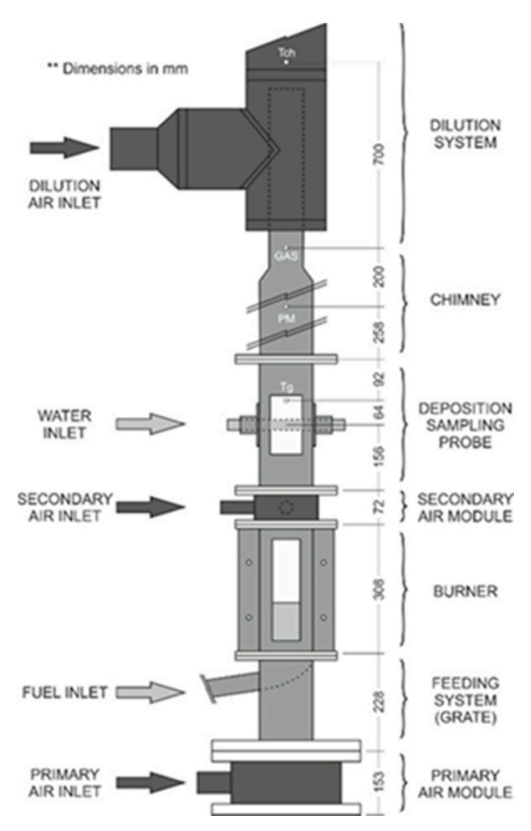

Figure 1. Scheme of the facility.

Measurements of the concentration and distribution of the particles were performed with a 13-steps low pressure impactor. The extraction tube and the impactor were heated to $130{ }^{\circ} \mathrm{C}$ to avoid condensation. Aluminum foils were used as substrates in the impactor. The gas composition was continuously determined using a Servomex 4900 gas analyzer.

A water-cooled temperature-controlled deposition probe was used to determine the fouling matter. It acts as a heat exchanger allowing the condensation and collection of residual matter over 
its surface. The working fluid temperature is suitably controlled, being maintained at $25-30{ }^{\circ} \mathrm{C}$ and directly measured at both the inlet and the outlet of the heat exchanger. It is necessary to control the temperature to ensure that this parameter does not affect to the results [13]. The tube is installed before starting the test and removed when the test is finished. The mass remaining on the tube is separated into two fractions: the attached mass, which is in contact with the tube surface and is difficult to remove, and the deposited mass, which is situated on the outside and is detached through movement of the sampling probe.

\subsection{Experimental Methodology}

To determine the stability of the plant, several series of preliminary tests were carried out. The test duration was set depending on the fuel as a function of the stability of each combustion process. In this study, the total airflow and the air staging were the main operative parameters.

The fouling was determined by gravimetric methods, collecting and sparing the material into two fractions according to the abovementioned method, and using a microbalance for mass measurements.

To analyze the slag produced by each fuel, a test methodology was established. The facility was thoroughly cleaned before starting the test and after the process is finished. After finishing the tests, the ash samples from the combustion chamber and in the ashtray (storage container of the ashes situated at the bottom of the combustor) were collected and weighted. The first samples were melted and fused ash (sintered depositions). After the first weighing, the residues were introduced into an oven at a temperature of $550{ }^{\circ} \mathrm{C}$ for $200 \mathrm{~min}$ to volatilize all unburned material and obtain the inert material, i.e., the final mass of the total slag residue.

\section{Results and Discussion}

\subsection{Chemical Properties}

The percentages of char and humidity are similar in all cases. The main differences were found in the volatile content and ash matter, the latter ranging from $0.54 \%$ in the commercial wood pellet to almost $13 \%$ on the $100 \%$ leaf pellet. In the elemental analysis, no large differences among the fuels were observed.

Ash is essentially formed from silicon, calcium and potassium [12]. The sum of these three elements exceeds, in all cases, $60 \%$ of the utilized fuels. However, the ashes of bp and lp100 are especially rich in these elements, comprising more than $90 \%$ of the fuels.

Some of the used pellets have a high ash content compared with other biomass fuels produced from biomass wastes [10]. However, the wood pellet used in this study has an ash content similar to other wood pellets [17-19]. The alkali index for wp and lp100 is lower than 0.17 , and, consequently, the fouling probability is small. Nevertheless, for bp and lp25, it is estimated that the fouling will be greater [20].

In the fuels used in this investigation, the base-acid ratio varies from 0.49 to 1.45 , according to Teixeira et al. [21], and the tendency of slag formation for these values is moderate. However, in accordance with other investigations [22], the tendency of slag formation based on the slagging ratio is low for the barley pellet, because its value is greater than 72; on the other hand, for 1p100, lp25 and wp, the tendency of slag formation is high because its value is less than 65. Finally, based on studies carried out by Pronobis et al. [23], the results obtained for the fouling indices indicate that the possibility of fouling is high in all cases.

\subsection{Physical Properties}

Table 3 summarizes the physical properties of the four input materials, along with other flow data. The table includes the measured effective angles of internal friction, $\delta_{\mathrm{e}}$, of the four biomass species studied (barley, leaves, leaves + sawdust mixture and sawdust). The value of the effective angle of internal friction for sawdust (wp) is shown to be larger than those for other materials. The highest 
value of the bulk density was determined for lp100 and lp25, which indicates that the bulk material takes up the smallest volume at the same weight in comparison with other materials.

Table 3. Physical and flow properties.

\begin{tabular}{ccccc}
\hline Raw Material & $\boldsymbol{\rho}_{\mathbf{b}}\left(\mathbf{k g} \cdot \mathbf{m}^{-3}\right)$ & $\boldsymbol{\delta}_{\mathbf{e}}\left(^{(}\right)$ & ffc $(-)$ & $\boldsymbol{\phi}\left(^{\circ}\right)$ \\
\hline bp & 148 & 27.0 & 27.3 & 13.1 \\
lp100 & 245 & 43.1 & 13.4 & 9.6 \\
lp25 & 221 & 45.0 & 10.7 & 14.8 \\
wp & 204 & 46.7 & 6.6 & 13.3 \\
\hline
\end{tabular}

Note: bulk density, $\rho_{\mathrm{b}}\left(\mathrm{kg} \cdot \mathrm{m}^{-3}\right)$; internal friction angle, $\delta_{\mathrm{e}}\left({ }^{\circ}\right)$; flow index, ffc $(-)$; and wall friction angle, $\phi\left(^{\circ}\right)$.

Figure 2 shows the flowability of the tested materials, which represents the strength of a bulk solid with a free surface. This graph indicates the ability of a bulk solid to form a cohesive arch during the discharge process, pelletization, storage, etc. According to the classification of powder flowability by the flow index (Table 3), the flow index values decrease counter-clockwise from the region of free flow to hard flow, as shown in Figure 2.

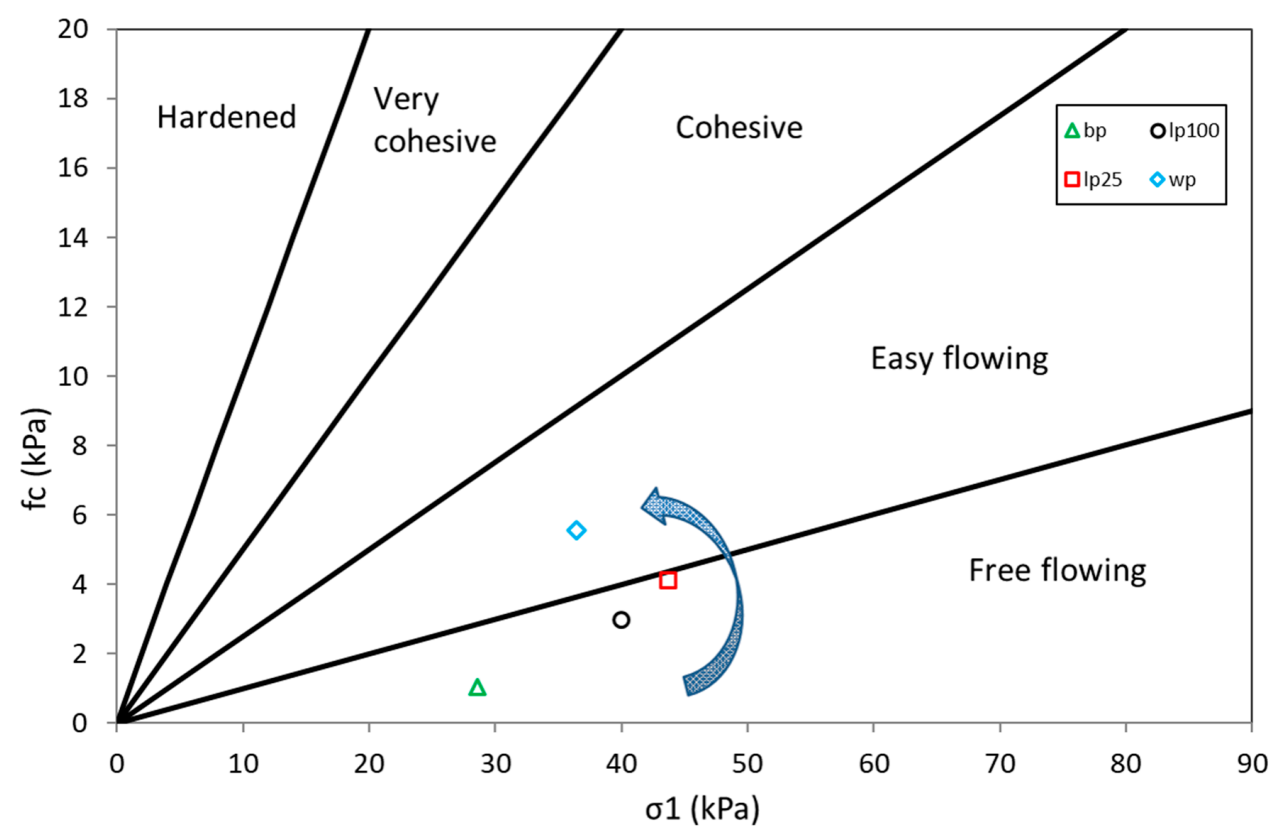

Figure 2. Flow functions of the raw input materials.

Barley and leaves belong to the free flowing region, the leaves-sawdust mixture is on the border of the two regions, and sawdust belongs to the easy flowing region. Sawdust (blue) tends to form smaller arches more easily than the leaves-sawdust mixture (red). It seems evident that the addition of leaves to sawdust improves the flowability of the mixture. Barley (green) was evaluated as a trouble-free material due to its flowability. Of course, flowability is a consequence of a combination of the material physical properties, such as moisture, particle-size distribution and so on, that influence the material flow and the equipment used for handling, storing or processing these materials [15]. The abovementioned conclusions are applicable only for the tested materials.

Wall friction measurements were conducted for each raw input material. The angle of wall friction values varied, ranging approximately $9-15^{\circ}$, as shown in Table 3 . The values describe how the materials flow across the stainless-steel wall surface. The design of hoppers depends on the values of the angle of internal friction and the angle of wall friction. 


\subsection{Stability of the Facility}

The duration of the steady combustion tests was inversely proportional to the fuel ash content $[5,10]$. Therefore, a certain testing time was established for each fuel according to their characteristics. To set the test length, preliminary experiments were performed by varying the air staging and the total airflow to establish the optimal parameters for combustion. The duration of the stable period was particularly low with some fuels (i.e., bp and lp100), although similar values were obtained in other investigations [5].

Table 4 contains the maximum duration of the tests to avoid fluctuations in combustion and the specific times of each stage in combustion tests. For a fuel with relatively good combustion properties, such as wood pellets, the performed experiments were typically $4 \mathrm{~h}$, although, in this facility, 5-h tests were also carried out [13]. The plant is able to operate longer than those intervals, but, after $5 \mathrm{~h}$, the negative effects of ash accumulation and unburned material in the bed, which jeopardizes combustion, becomes considerably appreciable. The length of the transient and shut down periods were the same regardless of the experiments, 45 and $15 \mathrm{~min}$, respectively, and only the stability period the varied.

Table 4. Duration of the tests for the four fuels used in this study.

\begin{tabular}{ccccc}
\hline & Total Duration (min) & Ignition (min) & Stability (min) & Shut Own (min) \\
\hline Pine pellet & 240 & 45 & 180 & 15 \\
Barley pellet & 105 & 45 & 45 & 15 \\
Leaf pellet 100\% & 100 & 45 & 40 & 15 \\
Leaf pellet 25\% & 150 & 45 & 90 & 15 \\
\hline
\end{tabular}

In Figure 3, the gas temperature $\left(\mathrm{T}_{\mathrm{g}}\right)$ in the area close to the heat exchanger is shown for the wood $(w p)$ and barley (bp) pellets. These two fuels were selected because they represent the extreme behavior of the facility, where wp is a reference, since it is the most widely used for combustion purposes among the biomasses studied in this paper. The system stability during steady-state combustion can be seen in both temperature curves, which remain practically constant during the central $45 \mathrm{~min}$. The observed oscillations are primarily generated by fluctuations in the fuel supply system. For the other materials, similar behavior was identified.

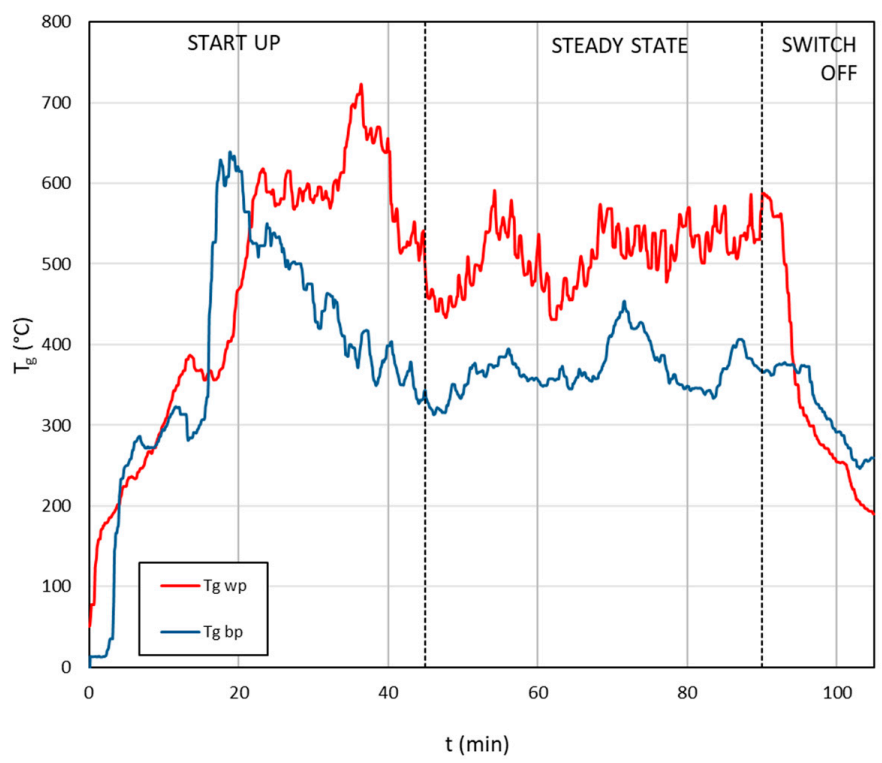

Figure 3. Time evolution and stability of the plant for a test with wp $\left(\psi_{1}=25 \% ; \dot{\mathrm{m}}_{\text {air }}^{\prime \prime}=0.457 \mathrm{~kg} / \mathrm{m}^{2} \mathrm{~s}\right.$; $\left.\dot{\mathrm{m}}_{\mathrm{f}}^{\prime \prime}=0.032 \mathrm{~kg} / \mathrm{m}^{2} \mathrm{~s}\right)$ compared with a test with $\mathrm{bp}\left(\psi_{1}=60 \% ; \dot{\mathrm{m}}_{\text {air }}^{\prime \prime}=0.528 \mathrm{~kg} / \mathrm{m}^{2} \mathrm{~s} ; \dot{\mathrm{m}}_{\mathrm{f}}^{\prime \prime}=0.044 \mathrm{~kg} / \mathrm{m}^{2} \mathrm{~s}\right)$. 


\subsection{Plant Repeatability}

To verify the repeatability of the plant, barley pellets (bp) with an ash content of $8.39 \%$ were used. Four tests with the same characteristics were carried out, and the relative deviations in the different parameters were calculated and are shown in Table 5, paying special attention to the combustion processes.

Table 5. Plant repeatability for a group of tests with bp: $\psi_{1}=60 \%, \psi_{2}=40 \%, \dot{\mathrm{m}}_{\text {air }}^{\prime \prime}=0.528 \mathrm{~kg} / \mathrm{m}^{2} \mathrm{~s}$ and $\mathrm{T}_{\text {in }}=30-35^{\circ} \mathrm{C}$.

\begin{tabular}{ccc}
\hline & & Relative Deviation (\%) \\
\hline \multirow{2}{*}{ Combustion parameters } & Burning rate $\left(\mathrm{kg} / \mathrm{m}^{2} \mathrm{~s}\right)$ & 17.82 \\
& Gas temperature $\left({ }^{\circ} \mathrm{C}\right)$ & 6.81 \\
\hline \multirow{2}{*}{ Fouling } & Deposited mass $\left(\mathrm{g} / \mathrm{m}^{2} \mathrm{~h}\right)$ & 10.04 \\
& Attached mass $\left(\mathrm{g} / \mathrm{m}^{2} \mathrm{~h}\right)$ & 13.00 \\
& Total mass $\left(\mathrm{g} / \mathrm{m}^{2} \mathrm{~h}\right)$ & 6.90 \\
\hline Particulate matter & Particulate matter $\left(\mathrm{mg} / \mathrm{Nm}^{3}\right)$ & 4.13 \\
\hline \multirow{2}{*}{ Gaseous emissions } & $\mathrm{O}_{2}$ measured $(\%)$ & 1.70 \\
& $\mathrm{CO}(\mathrm{ppm})$ & 8.24 \\
& $\mathrm{NO}_{\mathrm{x}}(\mathrm{ppm})$ & 5.77 \\
\hline
\end{tabular}

Examining the data in the table, most of the parameters have a relative deviation around $10 \%$, which indicates the good repetitiveness of the system and that the experimental device is able to work with different fuel types apart from common wood pellets.

\subsection{Combustion Parameters}

As mentioned above, three biomass species that had never been tested before were studied in this experimental facility. To determine the operating limits of each fuel type, seven series of combustion tests were performed. All results are represented in Figure 4, accompanied by an explicative table (Table 6) in which the total airflow, air staging and fuel type are specified for each experiment. As a general trend, a directly proportional relationship is observed between the primary airflow and the fuel flow [14].

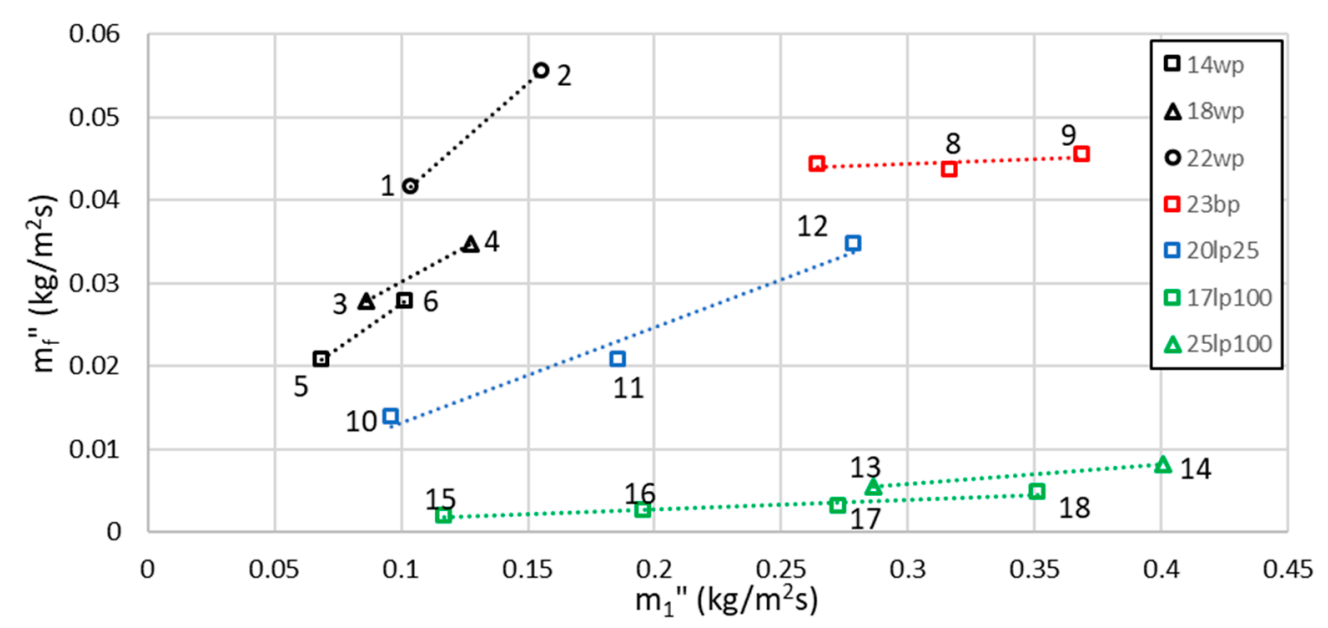

Figure 4. Operating limits for each tested fuel type: the black series correspond to wp trials performed with a total airflow of 14,18 and $22 \mathrm{~m}^{3} / \mathrm{h}$; the red and blue series refer to bp and lp25 performed with a total airflow of 23 and $20 \mathrm{~m}^{3} / \mathrm{h}$; and the green series represent lp100 tests carried out with a total airflow of 17 and $25 \mathrm{~m}^{3} / \mathrm{h}$. 
Table 6. Summary of combustion tests carried out in the experimental facility. The primary airflow portion, $\psi(\%)$, for each experiment is specified.

\begin{tabular}{ccc}
\hline Fuel & Test ID & $\boldsymbol{\psi} \mathbf{( \% )}$ \\
\hline \multirow{2}{*}{ wp } & $1,3,5$ & 20 \\
& $2,4,6$ & 30 \\
\hline \multirow{3}{*}{ bp } & 7 & 50 \\
& 8 & 60 \\
lf25 & 9 & 70 \\
\hline \multirow{3}{*}{ lf100 } & 10 & 20 \\
& 11 & 40 \\
& 12 & 60 \\
\hline & 15 & 30 \\
& 13,16 & 50 \\
& 14,17 & 70 \\
\hline
\end{tabular}

Regarding Figure 4, the operating limits of each studied fuel can be analyzed in terms of the combustion quality and power generated in the combustion device. In previous investigations, a directly proportional relationship between biomass consumption and the power of the plant was noticed [14]. A increasing behavior in fuel mass fed to the facility is usually accompanied by an increase in the thermal energy released per time unit [14]. According to the wp results, the curves show that the operating primary air amounts range between 0.07 and $0.16 \mathrm{~kg} / \mathrm{m}^{2} \mathrm{~s}$. For those cases, an adequate combustion behavior is observed, since large amounts of supplied pellets are required for relatively low primary air flows. Hence, this translates to a high power of the plant. However, the contrary case was found for the fuel made of leaves. Those combustion tests (from 13 to 18 in Figure 4) were performed with primary air flows in the range of 0.12 to $0.4 \mathrm{~kg} / \mathrm{m}^{2} \mathrm{~s}$, which is up to 2.5 times the airflow required for $w p$, while the feeding flow remained considerably low, below $0.01 \mathrm{~kg} / \mathrm{m}^{2} \mathrm{~s}$. That is, a poor combustion process is obtained when lp100 is used, inhibiting acceptable power production in the plant. This different behavior is associated with the physico-chemical properties of the used fuels, mainly the ash content $(0.55 \%$ for wp versus $12.97 \%$ for $1 p 100)$, which is related to slag formation and its resulting problems in combustion processes [24]. The bp and lp25 test results show intermediate curves, although the behavior of barley is certainly close to that of lp100 in regards to the high primary airflow needed to start the oxidative process. For both leaf pellets (lp25 and lp100), it can be observed that combustion requires large amounts of excess air (Figure 4), and their burning rates remain at considerably low levels, especially for lp100. Therefore, this phenomenon evinces the low suitability of this raw material for commercial use in biomass devices.

\subsection{Particulate Emissions}

In this section, particulate matter (PM) emissions are analyzed for each fuel. Figure 5 shows the PM concentrations obtained for each combustion test as a function of fuel type and primary air fraction. Regarding the air staging, it can be proven that the total amount of particles varies with the percentage of primary air, but the trend is not clear. Furthermore, it is clearly verified that the best results in terms of PM release are obtained with wp and the worst with bp. 


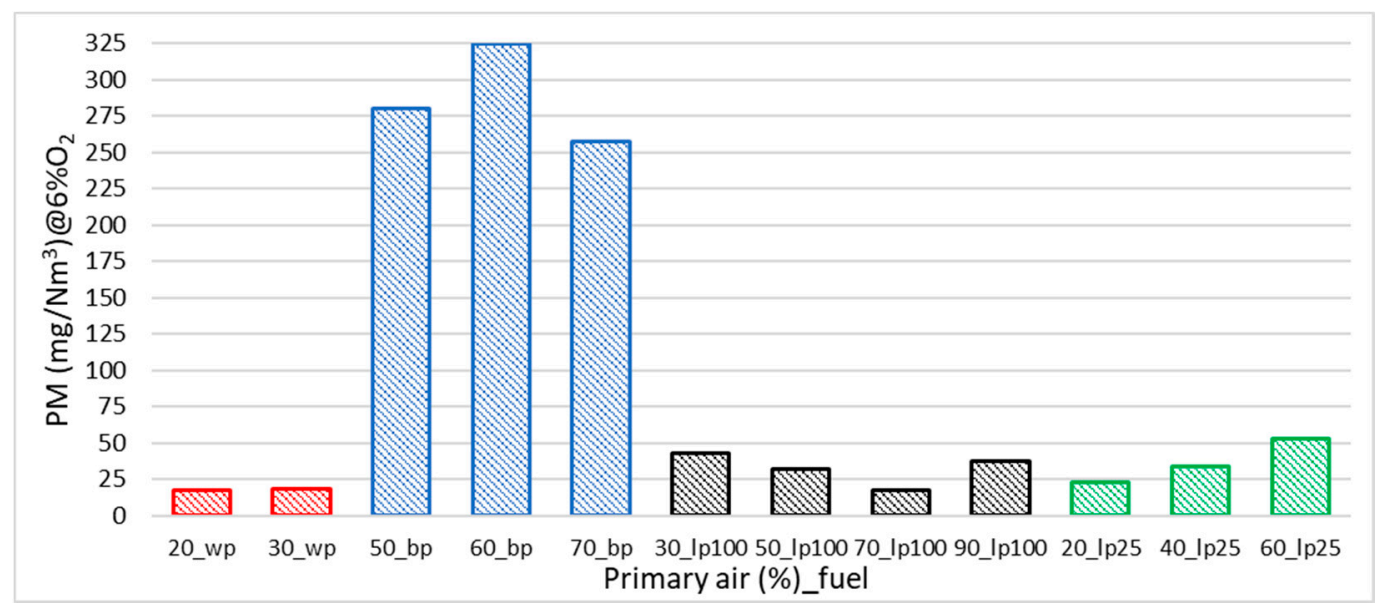

Figure 5. Particulate matter concentration of each fuel. The primary airflow and the fuel are specified on the x-axis. The total airflow used was: $\dot{\mathrm{m}}_{\text {air }}^{\prime \prime}=0.425 \mathrm{~kg} / \mathrm{m}^{2} \mathrm{~s}$ for $\mathrm{wp} ; \dot{\mathrm{m}}_{\text {air }}^{\prime \prime}=0.543 \mathrm{~kg} / \mathrm{m}^{2} \mathrm{~s}$ for bp; $\dot{\mathrm{m}}_{\text {air }}^{\prime \prime}=0.401 \mathrm{~kg} / \mathrm{m}^{2} \mathrm{~s}$ for lp100; and $\dot{\mathrm{m}}_{\text {air }}^{\prime \prime}=0.472 \mathrm{~kg} / \mathrm{m}^{2} \mathrm{~s}$ for $1 \mathrm{p} 25$.

The objective of varying the air staging was to establish a range of values for the particle concentration of each fuel. Currently, no data are available in the literature for the non-commercial pellets used in this work. However, there are numerous studies concerning wood pellets in small-scale boilers [25-27]. To verify the correct functioning of the facility, the results were compared with those of other plants with the same feeding fuel (wp) and were shown to agree with the available literature data. Therefore, once the correct operation of the combustor was established, the range of particle concentrations can be established for the three new fuels not analyzed previously. These values are given in Table 7. The particle concentration of bp is excessively high, and, consequently, this fuel is not suitable for use as a commercial pellet. However, the PM amounts obtained for lp100 and lp25 are close to that of the wood pellet.

Table 7. Summary of results obtained for the studied fuels, including PM data, type of particle-size distribution, data for the main size fraction (size and concentration) and fouling information.

\begin{tabular}{ccccccc}
\hline Fuel Type & wp ref & References & wp & bp & lp100 & 1p25 \\
\hline PM $\left(\mathrm{mg} / \mathrm{Nm}^{3}\right)$ & $13-34$ & {$[27,28,30,31]$} & $17.5-18$ & $257-325$ & $17-43$ & $22-53$ \\
Particle-size distribution & Unimodal and bimodal & {$[28]$} & Unimodal & Mixed & Unimodal & Unimodal \\
Particle-size peak $(\mathrm{nm})$ & $30-300$ & {$[30,32]$} & $30-100$ & $30-470$ & $30-300$ & $30-300$ \\
Conc. peak $\left(\mathrm{mg} / \mathrm{Nm}^{3}\right)$ & $28-240$ & {$[31,32]$} & $20-35$ & $120-140$ & $20-27$ & $8-31$ \\
Fouling $\left(\mathrm{g} / \mathrm{m}^{2} \mathrm{~h}\right)$ & $7-28$ & {$[13]$} & $6.3-14.4$ & $18.5-24.3$ & $6.9-26.4$ & $4.1-15.3$ \\
\hline
\end{tabular}

The particle-size distribution of PM in each type of biomass is presented in Figure 6. Observing the four graphs together, there is a slight tendency for the particle size to increase as the percentage of primary air increases. The homogeneity in the particle-size distribution for wp is higher, because the air staging used was slightly changed (from $20 \%$ to $30 \%$ primary air). Large increases in the total amount of primary air produces a greater tendency to drag the bed, which causes large particles to be released [28].

There are numerous studies concerning wood pellets in this kind of facility [27,28]. The majority of the studies have determined that the particle size is below $1 \mu \mathrm{m}$ [27-29] and that the distribution can be unimodal or bimodal depending on the position of the sampling point [28]. The results obtained for the four tested fuels are summarized in Table 7. Furthermore, it should be noted that the concentration and particle distribution are related to the fuel type. The worst results were obtained with bp due to the high concentration of the finest fraction $\left(140 \mathrm{mg} / \mathrm{Nm}^{3}\right.$ for bp versus $35 \mathrm{mg} / \mathrm{Nm}^{3}$ for wp). 

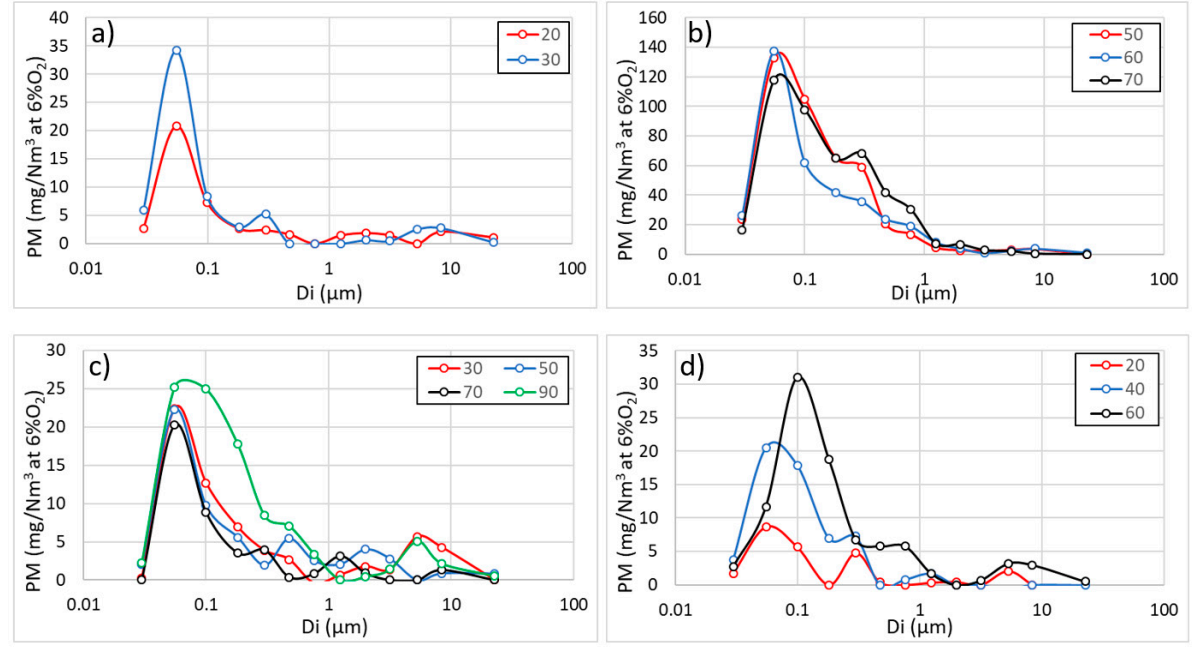

Figure 6. Particulate matter distribution for each test. The percentage of primary airflow is specified in the legend: (a) tests with wp and $\dot{\mathrm{m}}_{\text {air }}^{\prime \prime}=0.425 \mathrm{~kg} / \mathrm{m}^{2} \mathrm{~s}$; (b) tests with bp and $\dot{\mathrm{m}}_{\text {air }}^{\prime \prime}=0.543 \mathrm{~kg} / \mathrm{m}^{2} \mathrm{~s}$; (c) tests with $1 \mathrm{p} 100$ and $\dot{\mathrm{m}}_{\text {air }}^{\prime \prime}=0.401 \mathrm{~kg} / \mathrm{m}^{2} \mathrm{~s}$; and (d) tests with $1 \mathrm{p} 25$ and $\dot{\mathrm{m}}_{\text {air }}^{\prime \prime}=0.472 \mathrm{~kg} / \mathrm{m}^{2} \mathrm{~s}$.

\subsection{Fouling and Slagging}

In Figure 7, the fouling results are given for each fuel used in this study. As a general trend, comparing the tests carried out with the same biomass, the fouling rate increased as the total primary airflow increased. In previous studies, it was demonstrated that both the air staging and the total airflow are determining factors for the fouling rate [13]. In addition, the percentages of adhered mass show no clear trend. However, in analyzing the tests with the same fuel, the total amount of adhered mass increases as the percentage of primary air increases.

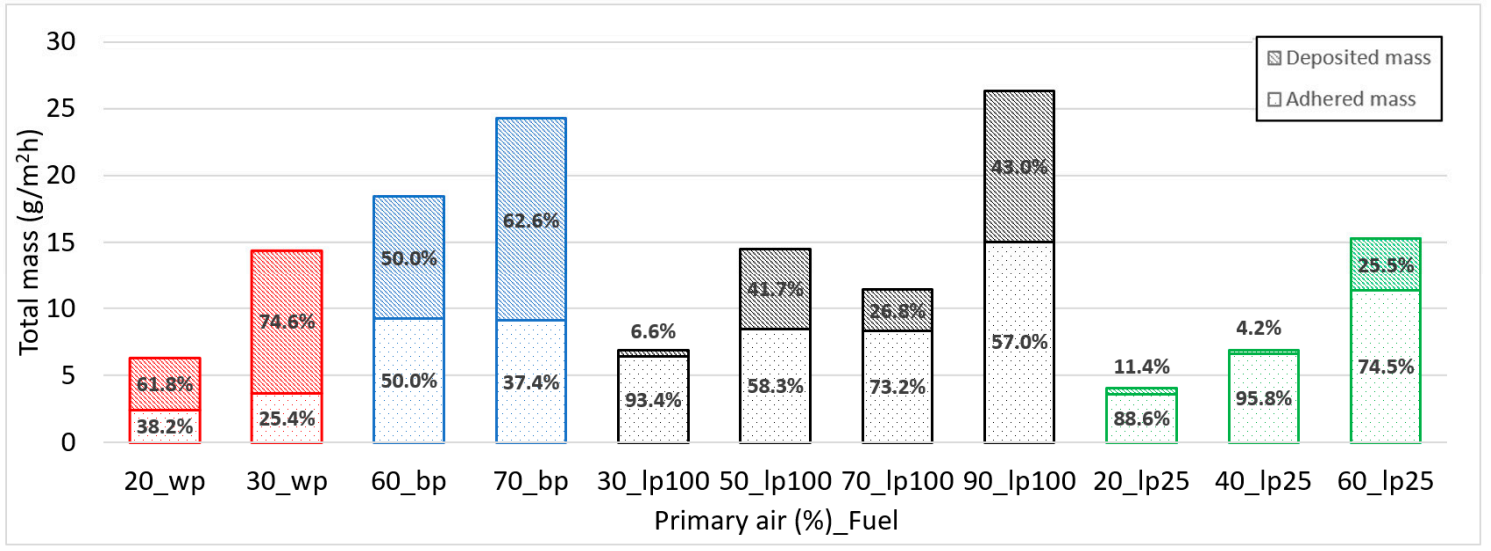

Figure 7. Deposited and attached mass for each fuel. The primary airflow and the fuel are specified in x-axis. The percentage of each mass is specified over the area that represents it. The total airflow used was: $\dot{\mathrm{m}}_{\text {air }}^{\prime \prime}=0.425 \mathrm{~kg} / \mathrm{m}^{2} \mathrm{~s}$ for wp; $\dot{\mathrm{m}}_{\text {air }}^{\prime \prime}=0.543 \mathrm{~kg} / \mathrm{m}^{2} \mathrm{~s}$ for bp; $\dot{\mathrm{m}}_{\text {air }}^{\prime \prime}=0.401 \mathrm{~kg} / \mathrm{m}^{2} \mathrm{~s}$ for $1 \mathrm{p} 100$; and $\dot{\mathrm{m}}_{\text {air }}^{\prime \prime}=0.472 \mathrm{~kg} / \mathrm{m}^{2} \mathrm{~s}$ for $\mathrm{lp} 25$.

In all cases, the fuel properties are the determinant parameter for the fouling rate, when fuels with very dissimilar properties are analyzed [33]. The fuel composition is related not only to the total amount of fouling but also to the percentage of each subtype (adhered mass + deposited mass) over the heat exchanger. The adhered mass is in contact with the heat exchanger surface and is mainly formed from potassium and chlorine, whereas the deposited mass is situated over the adhered mass layer and is formed from silicon, magnesium and iron [17]. 
A comparison between the four fuels is difficult to establish due to differences between the test characteristics. Following the previous scheme, the wp results can be compared with other investigations and are found to be in accordance with the literature [21]. However, since there are no data for the new non-commercial pellets, the value ranges are given in Table 7.

In relation to the fouling rate, none of the analyzed combustibles present a particularly high fouling rate compared with the commercial pellet. Therefore, based on this parameter, any of the pellets could be used commercially.

The slagging results for the three combustion tests with lp25 are represented in Figure 8. The slagging is only studied with this pellet because with the previous studied parameters the rest of the fuels were discarded for using as commercial fuels. In this test series, the varying parameter is the air staging, which is defined as the relationship between the primary and secondary air percentage. Observing the graph, the clinker rests do not contain practically volatile matter, independently of the test conditions, because the total amount of deposits before and after using the oven is almost the same. However, for the grate ashes, the mass variation after oven treatment is not negligible (variation values). This indicates that the ash rests contain a notable amount of volatile and unburned material. Furthermore, a slight tendency can be observed in the results: as the percentage of primary air decreases, the amount of volatile and unburned matter remaining in grate ashes increases. This is due to the poor oxidative conditions in cases of lower air entrance, such as 20/80 air staging, where the amount of oxidizing agent is not enough to complete the reaction for all of the fuel. The available data related to slagging allows the tuning of the amount of debris per kilogram of consumed fuel after combustion as well as the determination of the percentage of grate ashes, along with the sintered material produced and the percentage of organic matter not volatilized.

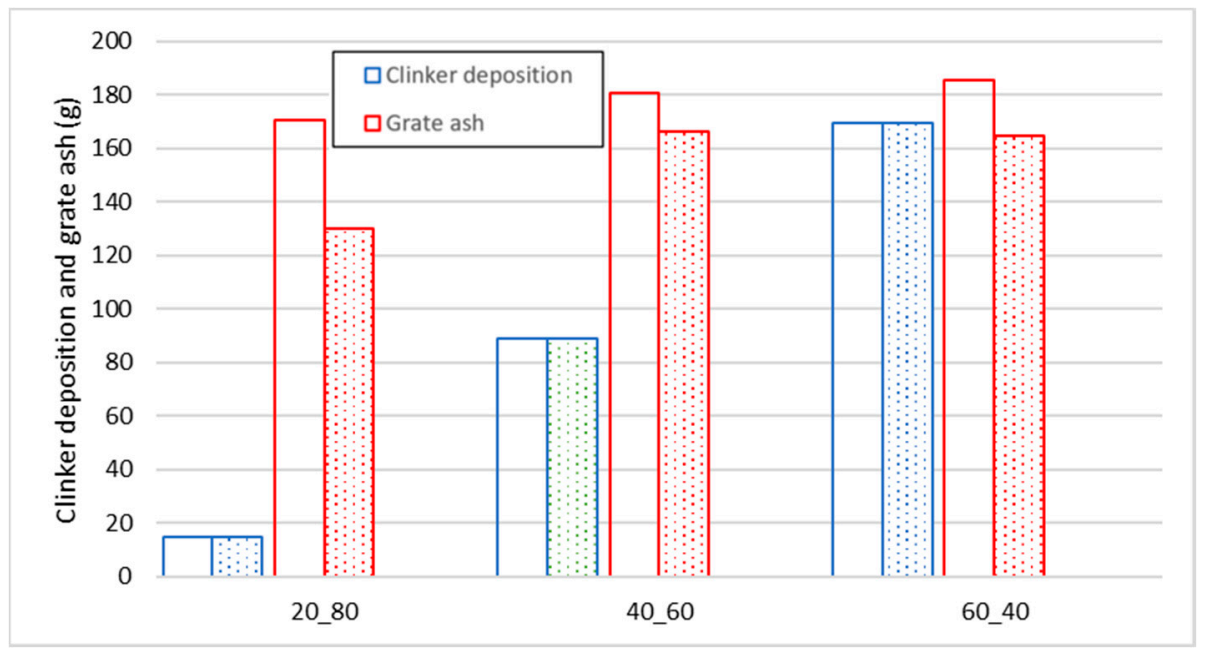

Figure 8. Slagging results for three different tests with lp25. The empty area represents the grate ash and clinker deposition mass before drying, and the dotted area represents the grate ash and clinker deposition mass after drying. The $x$-axis specifies the air staging (Primary (\%)_Secondary (\%)), and the total airflow was $\dot{\mathrm{m}}_{\text {air }}=0.457 \mathrm{~kg} / \mathrm{m}^{2} \mathrm{~s}$.

To further illustrate the global effects of air staging on the slagging, Figure 9 shows the results for three tests with different air staging. In these photographs, it can be seen that the clinker deposition size increases as the percentage of primary air flow also increases, keeping the total amount of flow constant. 


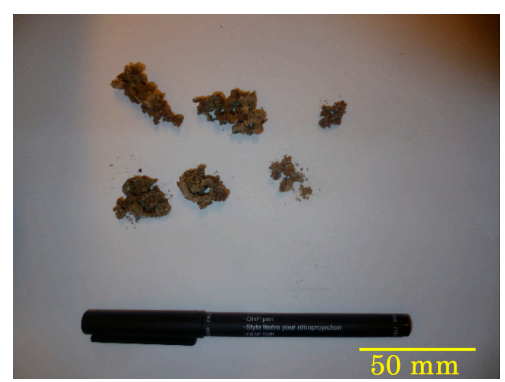

(a)

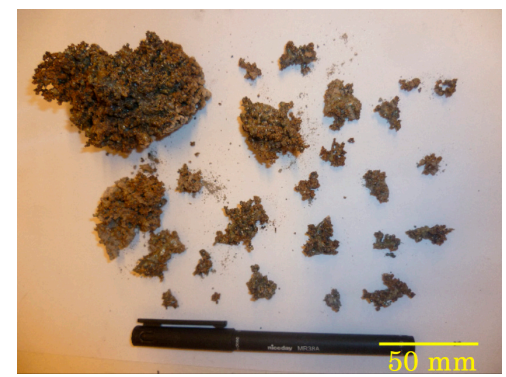

(b)

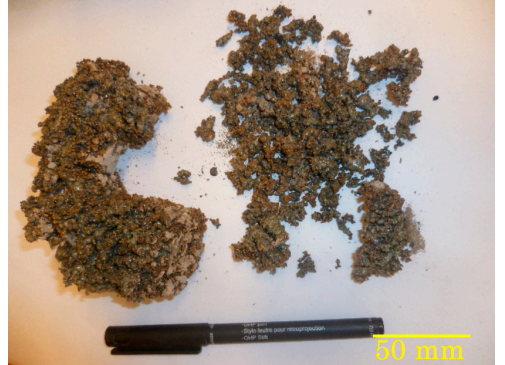

(c)

Figure 9. Slag collected in the combustion chamber for three tests with $1 \mathrm{p} 25$ and $\dot{\mathrm{m}}_{\text {air }}=0.472 \mathrm{~kg} / \mathrm{m}^{2} \mathrm{~s}$ : (a) $\psi_{1}=20 \%$; (b) $\psi_{1}=40 \%$; and (c) $\psi_{1}=60 \%$.

\section{Conclusions}

To determine the suitability of using three non-commercial pellets in domestic appliances, a testing methodology was established in this study. The investigation was carried out in an experimental biomass combustor. The stability of the facility was tested for the fuel with the worst operation. The results obtained for the three non-commercial pellets were compared with the results for wp (commercial pellet) in the same facility. The analyzed parameters were the burning rate, particulate matter, fouling and slagging. In any case, the relative deviation was always less than $10 \%$. The main conclusions drawn from the analyzed parameters for each fuel are given below.

A priori, under the tested conditions, bp and lp100 do not seem to be good choices for commercialization. However, lp25 is not a bad alternative, although its commercialization necessitates the use of additives to improve the fuel quality. The main conclusions drawn from the analyzed parameters for each fuel are given below.

- The test duration is directly related to the ash content in the fuel. The ash is accumulated in the bed after combustion. If very high temperatures are reached, part of the ash melts and forms slag, which worsens the combustion, causing instabilities and unwanted downtime. The test duration without transitory periods for the reference fuel (wp) was $180 \mathrm{~min}$. However, this value was reduced to 40 and $45 \mathrm{~min}$ for $1 \mathrm{p} 100$ and bp, respectively. For lp25, the duration was $90 \mathrm{~min}$.

- In the study of the operating limits of each fuel, the best results for the non-commercial pellets were obtained for $1 \mathrm{p} 25$, since the primary airflow needed to support combustion is relatively low for high fuel consumption. Furthermore, worse conditions were observed for the $100 \%$ leaf pellet, whose combustion required larger amounts of primary air to be employed, obtaining considerably low power values. Its high ash content led to a large accumulation of ash in the bed, which worsens combustion. In addition, a directly proportional relationship was found between the amount of primary air and fuel consumption.

- The particulate matter emission ranges were determined for the three new pellets. The concentration for wp was between 17.5 and $18 \mathrm{mg} / \mathrm{Nm}^{3}$ in this facility. The concentrations for bp, lp100 and lp25 were between 257 and $325 \mathrm{mg} / \mathrm{Nm}^{3}, 17$ and $43 \mathrm{mg} / \mathrm{Nm}^{3}$ and 22 and $53 \mathrm{mg} / \mathrm{Nm}^{3}$, respectively. The particle-size distribution is unimodal for all cases except bp, in which it is mixed. However, all particles are smaller than $1 \mu \mathrm{m}$. The size of the particles increases with the amount of primary air, because an entrainment phenomenon occurred in the bed. The mass size distribution peak was located between 30 and $470 \mathrm{~nm}$ for bp and in the range of 30 to $300 \mathrm{~nm}$ for lp100 and lp25.

- The fouling rates were similar to that obtained for wp. In all cases, independently of the used parameters, the fouling rate was located between 4.1 and $26.4 \mathrm{mg} / \mathrm{Nm}^{3}$. Related to this factor, all fuels were shown to have a good behavior. 
- Slagging residues were present to a greater extent for 1p100, associated with the high ash content of the fuel. There are two kinds of slag: sintered deposition and grate ash. The first is not practically volatile, while the presence of volatile matter is notable in the second.

- A priori, under the tested conditions, bp and lp100 do not seem to be good choices for commercialization. However, lp25 is not a bad alternative, although its commercialization necessitates the use of additives to improve the fuel quality.

Acknowledgments: This paper was conducted within the framework of the project LO1404: Sustainable development of CENET and CZ.1.05/2.1.00/19.0389: Research Infrastructure Development of the CENET. In addition, the authors acknowledge the financial support from the European Union's Horizon 2020 research and innovation programme under grant agreement No 760551.

Author Contributions: Araceli Regueiro and Raquel Pérez-Orozco performed the tests and collaborated in the manuscript write up. Lucie Jezerska prepared the non-commercial pellets for testing. David Patiño supervised the tests and the article writing. Martin Zidek designed and performed the experiments with raw materials. Jan Necas analyzed the data.

Conflicts of Interest: The authors declare no conflict of interest.

\section{Nomenclature}

$\begin{array}{ll}\dot{\mathrm{m}}_{1} " & \text { Primary air mass flow }\left(\mathrm{kg} / \mathrm{m}^{2} \mathrm{~s}\right) \\ \dot{\mathrm{m}}_{2}{ }^{\prime \prime} & \text { Secondary air mass flow }\left(\mathrm{kg} / \mathrm{m}^{2} \mathrm{~s}\right) \\ \dot{\mathrm{m}}_{\mathrm{f}}{ }^{\prime \prime} & \text { Fuel burning rate }\left(\mathrm{kg} / \mathrm{m}^{2} \mathrm{~s}\right) \\ \dot{\mathrm{m}}_{\mathrm{air}}{ }^{\prime \prime} & \text { Total air mass flow }\left(\dot{\mathrm{m}}_{1}{ }^{\prime}+\dot{\mathrm{m}}_{2}{ }^{\prime \prime}\right)\left(\mathrm{kg} / \mathrm{m}^{2} \mathrm{~s}\right) \\ \mathrm{T}_{\mathrm{g}} & \text { Gas temperature }\left({ }^{\circ} \mathrm{C}\right) \\ \mathrm{T}_{\mathrm{in}} & \text { Water inlet temperature }\left({ }^{\circ} \mathrm{C}\right) \\ \mathrm{fc}_{\mathrm{f}} & \text { Unconfined yield strength }(\mathrm{kPa}) \\ \mathrm{ffc} & \text { Flow index } \\ \mathrm{Greek} \text { Symbols } & \\ \delta_{\mathrm{e}} & \text { Effective angle of internal friction }\left(^{\circ}\right) \\ \sigma_{1} & \text { Major consolidation stress }(\mathrm{kPa}) \\ \rho_{\mathrm{b}} & \text { Bulk density }\left(\mathrm{kg} / \mathrm{m}^{3}\right) \\ \phi & \text { Angle of wall friction }\left({ }^{\circ}\right) \\ \lambda & \text { Air-exceed ratio } \\ \psi_{1} & \text { Primary airflow }(\%) \\ \psi_{2} & \text { Secondary airflow }(\%) \\ \psi & \text { Air staging ratio }(\% \text { Primary air } / \% \text { secondary air }) \\ \text { Abbreviation } & \\ \mathrm{bp} & \text { Barley pellet } \\ \mathrm{DLPI} & \text { Dekati Low Pressure Impactor } \\ \mathrm{lp} 25 & \text { Pellet with } 25 \% \text { leaf-75\% wood } \\ \mathrm{lp} 100 & \text { Leaf pellet } \\ \mathrm{PM} & \text { Particulate matter } \\ \mathrm{wp} & \text { Wood pellet } \\ & \end{array}$

\section{References}

1. Luque, R.; Herrero-Davila, L.; Campelo, J.M.; Clark, J.H.; Hidalgo, J.M.; Luna, D.; Marinas, J.M.; Romero, A.A. Biofuels: A technological perspective. Energy Environ. Sci. 2008, 1, 542-564. [CrossRef]

2. Verma, V.; Bram, S.; De Ruyck, J. Small scale biomass heating systems: Standards, quality labelling and market driving factors-an EU outlook. Biomass Bioenergy 2009, 33, 1393-1402. [CrossRef]

3. Fiedler, F. The state of the art of small-scale pellet-based heating systems and relevant regulations in Sweden, Austria and Germany. Renew. Sustain. Energy Rev. 2004, 8, 201-221. [CrossRef]

4. Verma, V.; Bram, S.; Gauthier, G.; De Ruyck, J. Evaluation of the performance of a multi-fuel domestic boiler with respect to the existing European standard and quality labels: Part-1. Biomass Bioenergy 2011, 35, 80-89. [CrossRef] 
5. Cardozo, E.; Erlich, C.; Alejo, L.; Fransson, T.H. Combustion of agricultural residues: An experimental study for small-scale applications. Fuel 2014, 115, 778-787. [CrossRef]

6. Gilbe, C.; Ohman, M.; Lindström, E.; Boström, D.; Backman, R.; Samuelsson, R.; Burvall, J. Slagging characteristics during residential combustion of biomass pellets. Energy Fuels 2008, 22, 3536-3543. [CrossRef]

7. Dias, J.; Costa, M.; Azevedo, J. Test of a small domestic boiler using different pellets. Biomass Bioenergy 2004, 27, 531-539. [CrossRef]

8. Verma, V.; Bram, S.; Delattin, F.; Laha, P.; Vandendael, I.; Hubin, A.; De Ruyck, J. Agro-pellets for domestic heating boilers: Standard laboratory and real life performance. Appl. Energy 2012, 90, 17-23. [CrossRef]

9. Roy, M.M.; Dutta, A.; Corscadden, K. An experimental study of combustion and emissions of biomass pellets in a prototype pellet furnace. Appl. Energy 2013, 108, 298-307. [CrossRef]

10. Öhman, M.; Boman, C.; Hedman, H.; Nordin, A.; Boström, D. Slagging tendencies of wood pellet ash during combustion in residential pellet burners. Biomass Bioenergy 2004, 27, 585-596. [CrossRef]

11. Örberg, H.; Jansson, S.; Kalén, G.; Thyrel, M.; Xiong, S. Combustion and slagging behavior of biomass pellets using a burner cup developed for ash-rich fuels. Energy Fuels 2014, 28, 1103-1110. [CrossRef]

12. Lindström, E.; Larsson, S.H.; Boström, D.; Öhman, M. Slagging characteristics during combustion of woody biomass pellets made from a range of different forestry assortments. Energy Fuels 2010, 24, 3456-3461. [CrossRef]

13. Regueiro, A.; Patiño, D.; Granada, E.; Porteiro, J. Experimental study on the fouling behaviour of an underfeed fixed-bed biomass combustor. Appl. Therm. Eng. 2017, 112, 523-533. [CrossRef]

14. Regueiro, A.; Patiño, D.; Porteiro, J.; Granada, E.; Míguez, J.L. Effect of Air Staging Ratios on the Burning Rate and Emissions in an Underfeed Fixed-Bed Biomass Combustor. Energies 2016, 9, 940. [CrossRef]

15. Febrero, L.; Granada, E.; Patiño, D.; Eguía, P.; Regueiro, A. A comparative study of fouling and bottom ash from woody biomass combustion in a fixed-bed small-scale boiler and evaluation of the analytical techniques used. Sustainability 2015, 7, 5819-5837. [CrossRef]

16. Patiño, D.; Crespo, B.; Porteiro, J.; Míguez, J.L. Experimental analysis of fouling rates in two small-scale domestic boilers. Appl. Therm. Eng. 2016, 100, 849-860. [CrossRef]

17. Rashidian, B.; Al-Abdeli, Y.M.; Patiño, D.; Guzzomi, F.G.; Yeoh, G.H. Effect of freeboard deflectors in the fixed bed combustion of biomass. Appl. Therm. Eng. 2016, 103, 543-552. [CrossRef]

18. Jenkins, B.; Baxter, L.; Miles, T. Combustion properties of biomass. Fuel Process. Technol. 1998, 54, 17-46. [CrossRef]

19. Teixeira, P.; Lopes, H.; Gulyurtlu, I.; Lapa, N.; Abelha, P. Evaluation of slagging and fouling tendency during biomass co-firing with coal in a fluidized bed. Biomass Bioenergy 2012, 39, 192-203. [CrossRef]

20. Tchapda, A.H.; Pisupati, S.V. A review of thermal co-conversion of coal and biomass/waste. Energies 2014, 7, 1098-1148. [CrossRef]

21. Pronobis, M. Evaluation of the influence of biomass co-combustion on boiler furnace slagging by means of fusibility correlations. Biomass Bioenergy 2005, 28, 375-383. [CrossRef]

22. Ganesan, V.; Rosentrater, K.A.; Muthukumarappan, K. Flowability and handling characteristics of bulk solids and powders-A review with implications for DDGS. Biosyst. Eng. 2008, 101, 425-435. [CrossRef]

23. Khodaei, H.; Guzzomi, F.; Yeoh, G.H.; Regueiro, A.; Patiño, D. An experimental study into the effect of air staging distribution and position on emissions in a laboratory scale biomass combustor. Energy 2017, 118, 1243-1255. [CrossRef]

24. Gilbe, C.; Lindström, E.; Backman, R.; Samuelsson, R.; Burvall, J.; Ohman, M. Predicting slagging tendencies for biomass pellets fired in residential appliances: A comparison of different prediction methods. Energy Fuels 2008, 22, 3680-3686. [CrossRef]

25. Chen, Q.; Zhang, X.; Bradford, D.; Sharifi, V.; Swithenbank, J. Comparison of emission characteristics of small-scale heating systems using biomass instead of coal. Energy Fuels 2010, 24, 4255-4265. [CrossRef]

26. Johansson, L.S. Characterisation of Particle Emissions from Small-Scale Biomass Combustion; Chalmers Tekniska Högsk: Göteborg, Sweden, 2002.

27. Wiinikka, H.; Gebart, R.; Boman, C.; Boström, D.; Öhman, M. Influence of fuel ash composition on high temperature aerosol formation in fixed bed combustion of woody biomass pellets. Fuel 2007, 86, 181-193. [CrossRef]

28. Fernandes, U.; Costa, M. Formation of fine particulate matter in a domestic pellet-fired boiler. Energy Fuels 2013, 27, 1081-1092. [CrossRef] 
29. Wiinikka, H.; Gebart, R. Critical parameters for particle emissions in small-scale fixed-bed combustion of wood pellets. Energy Fuels 2004, 18, 897-907. [CrossRef]

30. Gaegauf, C.; Wieser, U.; Macquat, Y. In Field investigation of nanoparticle emissions from various biomass combustion systems. In Proceedings of the International Seminar on Aerosol from Biomass Combustion, Zurich, Switzerland, 27 June 2001; pp. 81-85.

31. Obernberger, I.; Brunner, T.; Bärnthaler, G. In Fine particulate emissions from modern Austrian small-scale biomass combustion plants. In Proceedings of the 15th European Biomass Conference \& Exhibition, Florence, Italy, 17 May 2007; pp. 1546-1557.

32. Johansson, L.; Tullin, C.; Leckner, B.; Sjövall, P. Particle emissions from biomass combustion in small combustors. Biomass Bioenergy 2003, 25, 435-446. [CrossRef]

33. Theis, M.; Skrifvars, B.-J.; Hupa, M.; Tran, H. Fouling tendency of ash resulting from burning mixtures of biofuels. Part 1: Deposition rates. Fuel 2006, 85, 1125-1130. [CrossRef]

2017 by the authors. Licensee MDPI, Basel, Switzerland. This article is an open access article distributed under the terms and conditions of the Creative Commons Attribution (CC BY) license (http://creativecommons.org/licenses/by/4.0/). 